\title{
Serum matrix metalloproteinase 2 and tissue inhibitor of matrix metalloproteinases 2 in esophageal cancer patients
}

\author{
Magdalena Groblewska1, Barbara Mroczko', Miroslaw Kozlowski², \\ Jacek Niklinski², Jerzy Laudanski², Maciej Szmitkowski ${ }^{1}$ \\ ${ }^{1}$ Department of Biochemical Diagnostics, Medical University, Białystok, Poland \\ ${ }^{2}$ Department of Thoracic Surgery, Medical University, Białystok, Poland
}

\begin{abstract}
The positive expression of MMP-2 and TIMP-2 were found in esophageal cancer (EC) tissue and correlated with cancer stage and clinico-pathological features of tumor and patients' survival. However, little is known about serum levels of those proteins in EC patients. The aim of the present study was to investigate the diagnostic significance of MMP-2 and TIMP-2 serum levels in EC patients in relation to clinico-pathological features of cancer. The study included 53 EC patients and 92 healthy controls. The serum levels of MMP-2, TIMP-2 and classical tumor markers CEA (carcinoembryonic antigen) and SCC (squamous cell carcinoma antigen) were assayed. The prognostic values and diagnostic criteria for the biomarkers tested were defined. Serum levels of MMP-2, TIMP-2 in EC patients were significantly lower, whereas CEA and SCC significantly higher than in control group. The diagnostic sensitivity of TIMP-2 $(57 \%)$ was higher than those for other biomarkers tested and increased in combination with SCC (70\%). Area under ROC curve for TIMP-2 (0.8698) was larger than for other proteins. In Cox's univariate analysis only SCC serum levels were significant prognostic factors for EC patients' survival. The results suggest the limited value of serum analyses of MMP-2 for tumor staging and prognosis in EC and the better usefulness of TIMP-2 than MMP-2 as a tumor marker in the diagnosis of EC, especially in combined use with SCC. (Folia Histochemica et Cytobiologica 2012, Vol. 50, No. 4, 590-598)
\end{abstract}

Key words: esophageal cancer; matrix metalloproteinase 2; tissue inhibitor of matrix metalloproteinases 2; CEA; SCC; tumor marker; survival

\section{Introduction}

Esophageal cancer (EC) belongs to the most common and aggressive tumors of the alimentary tract, and the frequency of new cases of EC still increases in the Western Europe and USA [1,2]. This malignancy is the sixth leading cause of cancer death in the world [3]. Eighty percent of esophageal cancer cases occur in developing countries [4]. The mortality and

Correspondence addresse: $\mathrm{M}$. Groblewska Department of Biochemical Diagnostics, Medical University, Białystok

Waszyngtona st. 15 a, 15-269 Białystok, Poland; tel.: +48 857468 587, fax: +48 857468 585;

e-mail: bialka@umb.edu.pl incidence rates of EC are often similar, the reason of that is the relatively late stage of diagnosis and rapid clinical progression $[5,6]$.

Development of malignant tumors is a long-term and multi-step process resulting in rapid growth and invasion into lymphatic and blood vessels [7]. The migration of tumor cells depends on the degradation of the extracellular matrix, which can be regulated by complex control of the expression and activity of matrix metalloproteinases (MMPs), a family of zinc-dependent endopeptidases, and their natural inhibitors tissue inhibitors of matrix metalloproteinases (TIMPs) [7-9]. Remodeling of normal and tumoral tissue may be a result of aberrations in dynamic balance between MMPs and TIMPs. It was shown that degradation of basement membrane and invasion of epithelium is the first step of tumor development and metastasis [10]. 
It was proved that matrix metalloproteinase 2 (MMP-2) and tissue inhibitor of matrix metalloproteinases 2 (TIMP-2) are involved in tumor invasion and metastasis in case of breast, gastric, pancreatic and colorectal cancer [11-14]. It was also suggested, that MMP-2 might play an important role in carcinogenesis of esophageal squamous cell cancer (ESCC) and could act as a biological marker of invasion and lymph node metastasis in this type of tumor. The overexpression of MMP-2 was found in ESCC tumor samples and was significantly associated with cancer stage, depth of tumor invasion and presence of lymph node metastases [15]. Moreover, the polymorphism in the MMP-2 promoter contributed to risk of the occurrence and metastasis of esophageal squamous cell carcinoma by increasing expression of MMP-2 [16].

Sharma et al. have shown the positive expression of TIMP- 1 and TIMP- 2 in $66 \%$ and $72 \%$ ESCC cases, respectively [17]. The expression of TIMP-2 in EC tumor tissue was associated with tumor size [17]. Moreover, they revealed that TIMP-1(+)/TIMP-2(+) phenotype inversely correlated with nodal invasiveness of the tumor and MMP-11(+)/TIMP-2(-) phenotype might be a significant predictive factor for disease-free survival in ESCC patients [17]. The survival analysis in their study showed that patients with TIMP-2-negative carcinoma had a significantly shorter disease-free survival as compared to TIMP-2-positive patients. Additionally, an increased expression of TIMP-2 was observed in 50\% dysplasias of esophagus, what also suggests that these alterations are early events in esophageal tumorigenesis [17]. An inverse correlation between expression of TIMP-2 and invasive ability of ESCC was found by Chen et al. [18].

However, there is a little known about serum levels of MMP-2 and TIMP-2 in esophageal cancer patients in comparison to healthy subjects and commonly used tumor markers such as CEA (carcinoembryonic antigen) and SCC (squamous cell carcinoma antigen) [19]. Therefore, the aim of the present study was to investigate the clinical importance of the determination of serum levels of MMP-2 and TIMP-2 in patients with esophageal cancer in relation to clinico-pathological features of cancer and to compare these levels with healthy subjects (control group). Additionally, we measured serum levels of classical tumor markers (SCC and CEA). Moreover, we assessed the diagnostic sensitivity and areas under ROC curves (AUC) for all the proteins tested as well as their prognostic significance in EC patients' survival.

\section{Material and methods}

Patients. The study included 53 previously untreated esophageal cancer patients (11 women and 42 men, aged 44-81 years) diagnosed and operated on by Thoracic Surgery Department of the Białystok Medical University Hospital and 92 healthy volunteers as control group (61 women and 31 men, aged 21-65 years).

The clinical diagnosis of EC was confirmed by microscopic examination of the material obtained during endoscopic examination and/or surgery. Twenty-six EC patients underwent surgical resection of the tumor, while twenty seven patients had non-resectable tumors. Resection of tumor was assessed as microscopically complete (R0) in 25 EC patients, macroscopically complete (R1) in 2 cancer patients and as micro- and macroscopically incomplete (R2) in 3 patients. In 23 patients the assessment of completeness of resection was not possible. Twenty-six EC patients died of cancer during the 4-year observation period, whereas 27 patients survived.

The staging was based on a routine histopathological analysis and clinical assessment, according to TNM (tumor-nodulus-metastases) classification. The tumors were classified in accordance with the staging of the 5th International Union Against Cancer [20]. The subjects who had suffered a heart failure or heart attack were excluded from the study as well as the patients after preoperative radio-chemotherapy.

In the study the following physical and pathological factors were evaluated: tumor size, depth of tumor invasion ( $\mathrm{T}$ factor), lymph node metastasis ( $\mathrm{N}$ factor), presence of distant metastasis ( $\mathrm{M}$ factor) and completeness of tumor resection (R). For the statistical analyses, the EC patients were divided into five groups according TNM classification: 1 cancer patient in stage I, 11 patients in stage IIA, 1 patient in stage IIB, 30 patients in stage III and 10 patients in stage IV. Moreover, we divided the cancer patients into: two groups depending on tumor size (patients with tumors below $4 \mathrm{~cm}$ and those with tumors of $4 \mathrm{~cm}$ or greater), four groups depending on the depth of tumor invasion (T1, T2, T3, and T4), two groups depending on nodal involvement (N0 and N1), two groups depending on the presence of distant metastases (M0 and M1). The number of patients in the analyzed subgroups are presented in Table 1 . The study was approved by the local ethics committee, the reference number is R-I-002/442/2010. All the patients gave their informed consent to participate in the study.

Protein analyses. Blood samples from all the patients were drawn before surgical treatment. None of the EC patients had received chemo- or radiotherapy before blood sample collection. All sera were separated within 1 hour after blood collection to standardize clotting conditions and stored at $-80^{\circ} \mathrm{C}$ until assayed.

Serum levels of MMP-2 and TIMP-2 were measured using enzyme-linked immunosorbent assay kits (ELISA) (R\&D Systems, Abingdon, England) according to the manufacturer's instructions. The serum samples were diluted 10-fold before determination of MMP-2 and 50-fold before measurement of TIMP-2. The intra-assay coefficient of vari- 
Table 1. Characteristics of esophageal cancer patients

\begin{tabular}{|c|c|}
\hline Variable tested & $\begin{array}{c}\text { Number } \\
\text { of patients }\end{array}$ \\
\hline \multicolumn{2}{|l|}{ Group } \\
\hline Esophageal cancer & 53 \\
\hline Control group & 92 \\
\hline \multicolumn{2}{|l|}{ Gender } \\
\hline Male & 42 \\
\hline Female & 11 \\
\hline \multicolumn{2}{|l|}{ Type of cancer } \\
\hline Adenocarcinoma & 23 \\
\hline Planoepitheliale & 30 \\
\hline \multicolumn{2}{|l|}{ TNM stage } \\
\hline I & 1 \\
\hline IIA & 11 \\
\hline IIB & 1 \\
\hline III & 30 \\
\hline IV & 10 \\
\hline \multicolumn{2}{|l|}{ Depth of tumor invasion ( $\mathrm{T}$ factor) } \\
\hline $\mathrm{Tl}$ & 1 \\
\hline $\mathrm{T} 2$ & 8 \\
\hline $\mathrm{T} 3$ & 27 \\
\hline $\mathrm{T} 4$ & 17 \\
\hline \multicolumn{2}{|l|}{ Nodal involvement ( $\mathrm{N}$ factor) } \\
\hline No & 13 \\
\hline N1 & 40 \\
\hline \multicolumn{2}{|l|}{ Distant metastases ( $\mathrm{M}$ factor) } \\
\hline M0 & 43 \\
\hline M1 & 10 \\
\hline \multicolumn{2}{|l|}{ Tumor size } \\
\hline$<4 \mathrm{~cm}$ & 15 \\
\hline$\geq 4 \mathrm{~cm}$ & 38 \\
\hline \multicolumn{2}{|l|}{ Differentiation of tumor } \\
\hline Well differentiated - G1 & 10 \\
\hline Moderately differentiated - G2 & 25 \\
\hline Undifferentiated — G3 & 16 \\
\hline \multicolumn{2}{|l|}{ Resection of tumor } \\
\hline $\mathrm{R} 0$ - microscopically complete & 25 \\
\hline $\mathrm{R} 1$ - macroscopically complete & 2 \\
\hline $\mathrm{R} 2$ - micro- and macroscopically incomplete & 3 \\
\hline Not available & 23 \\
\hline \multicolumn{2}{|l|}{ Survival of patients } \\
\hline Alive & 27 \\
\hline Died of cancer & 26 \\
\hline
\end{tabular}

ation $(\mathrm{CV} \%)$ of MMP-2 is reported by the manufacturer to be $5.8 \%$ at a mean concentration of $18.9 \mathrm{ng} / \mathrm{mL}, \mathrm{SD}=1.1$ and of TIMP-2 - to be $4.4 \%$ at a mean concentration of $1.23 \mathrm{ng} / \mathrm{mL}, \mathrm{SD}=0.054$.
Serum concentrations of CEA were measured by microparticle enzyme immunoassay kits (MEIA) (Abbott, Chicago, Illinois). The intra-assay $\mathrm{CV}$ for CEA is reported by the manufacturer of the assay kits to be $4.9 \%$ at a mean concentration of $2.2 \mathrm{ng} / \mathrm{mL}, \mathrm{SD}=0.11$.

The concentrations of SCC-Ag were determined by chemiluminescent assays (CMIA) (Abbott Japan Co., Ltd., Tokyo, Japan) and the intra-assay CV\% for SCC-Ag is referred to by the manufacturer of the assay kits as $4.3 \%$ at $\mathrm{SCC}-\mathrm{Ag}$ mean concentration of $1.97 \mathrm{ng} / \mathrm{mL}, \mathrm{SD}=0.085$.

The cut-off points for serum levels of MMP-2 (150.8 ng/ $/ \mathrm{mL})$ and TIMP-2 (73.75 ng/mL) were determined using Microsoft Office Excel software. In the ROC report generated by this program, the cut-off values corresponded to the highest accuracy (minimal false-negative and false-positive results). The positive results of MMP-2 and TIMP-2 are below cut-off values. The reference cut-off value for CEA and SCC were established previously in our department [21]. The cut-off points were $4.0 \mathrm{ng} / \mathrm{mL}$ for CEA and $2.0 \mathrm{ng} / \mathrm{mL}$ for SCC.

Statistical analysis. A preliminary statistical analysis $\left(\chi^{2}\right.$ test) revealed that serum levels of MMP-2, TIMP-2, CEA and SCC did not follow a normal distribution. Therefore, nonparametric statistical analyses were used. The stages I, IIA and IIB were analyzed as one group (stage I + IIA + IIB) because of small numbers of patients in the particular subgroups. Similarly, the T1 and T2 patients were analyzed as $\mathrm{T} 1+\mathrm{T} 2$ subgroup, and resection of tumors as $\mathrm{R} 0$ and nonresectable groups (R1 + R2 + not available for assessment).

The Mann-Whitney U-test was used to compare the two groups in each category (EC and healthy controls; adenocarcinoma of esophagi versus planoepithelial cancer; patients with tumors below $4 \mathrm{~cm}$ versus those with tumors $4 \mathrm{~cm}$ or greater; N0 versus N1 patients; M0 versus M1 group; R0 tumors versus nonresectable). Additionally, we compared each subgroup of cancer patient with control group using the Mann-Whitney test. Differences between more than two groups (e.g. stage I + IIA + IIB, III, IV and T1 + T2, T3, T4 tumors) were compared using Kruskal-Wallis tests. When significant differences were found, the post hoc Dwass-Steele-Critchlow-Fligner test was conducted to determine which groups were different. The Spearman rank correlation test was employed for the correlation analyses. Univariate analyses of survival were performed using the log-rank test, and multivariate analyses employed Cox's proportional hazards model. For all multivariate analyses, forward stepwise procedures were used. Differences were considered statically significant with $\mathrm{p}$ values below 0.05 .

Moreover, we calculated diagnostic criteria, such as percentage of true positive values (diagnostic sensitivity) and area under the receiver operating characteristic (ROC) curve (AUC) for the MMP-2, TIMP-2 and tumor markers. The 95 per cent confidence intervals (95\% C.I.) for diagnostic 
sensitivities were calculated using Wilson score method without continuity correction (22). Statistical analyses were carried out using the STATISTICA 9.0 PL program (StatSoft Inc., Tulsa, OK). Diagnostic criteria and the ROC curves were calculated using Med-Calc statistical software (MedCalc Software, Mariakerke, Belgium) and Microsoft Office Excel program (Microsoft Corporation, Redmond, WA).

\section{Results}

\section{Serum levels of MMP-2 and TIMP-2 in esophageal cancer patients}

Concentrations of MMP-2, TIMP-2 and tumor markers in the sera of EC patients as well as in healthy subjects are presented in Table 2. Serum levels of MMP-2 and TIMP-2 were lower, but tumor markers higher in EC patients than in healthy controls and the differences were significant for all proteins tested. Additionally, the concentrations of MMP-2 and TIMP-2 were significantly lower but CEA significantly higher in patients with adenocarcinoma and with planoepithelial cancer of esophagus than in control group. Moreover, the serum levels of SCC in planoepithelial cancer patients were significantly higher than in patients with adenocarcinoma of esophagus and healthy subjects.

Serum levels of MMP-2 and TIMP-2 did not correlate with tumor stage and were the lowest in the sera of EC patients with stage III, but serum levels of CEA and SCC increased and the highest values were observed in patients with most advanced cancer. The differences between cancer stages were significant only for CEA in Kruskal-Wallis test $(p=0.026)$ and were confirmed in post hoc Dwass-Steel-CritchlowFligner test for comparison between patients with stage II and III of EC. Moreover, the concentrations of MMP-2 and TIMP-2 in all cancer stages were significantly lower but CEA significantly higher in comparison with healthy controls.

Serum MMP-2 were higher, but TIMP-2 lower in EC patients with $\mathrm{R} 0$ tumors compared to those with nonresectable, although the differences were not statistically significant. Median concentrations of tumor markers in both subgroups were equal.

\section{Serum levels of MMP-2, TIMP-2, CEA and SCC in EC patients in relation to clinico-pathological features of tumor}

Table 3 presents concentrations of MMP-2, TIMP-2, CEA and SCC in the sera of EC patients in relation to clinico-pathological features of tumor. The concentrations of MMP-2 and TIMP-2 were lower, where- as CEA higher in patients with tumors of $4 \mathrm{~cm}$ or greater when compared to the tumors below $4 \mathrm{~cm}$, although the differences were significant only for CEA. Moreover, the levels of MMP-2 in patients with tumors greater than $4 \mathrm{~cm}$ and TIMP-2 in both subgroups of patients were significantly lower than in healthy subjects.

Serum levels of all proteins tested varied according to bowel wall infiltration ( $\mathrm{T}$ factor). Concentrations of MMP-2 were the lowest in the T4 subgroup, TIMP-2 - in $\mathrm{T} 1+\mathrm{T} 2$ patients, and tumor markers the highest in T4 tumors, although all these differences were not significant. Moreover, the concentrations of MMP-2 and TIMP-2 in all subgroups were significantly lower in comparison to healthy subjects. Additionally, the serum levels of CEA in T3 and T4 patients were significantly higher than in control group.

In patients with metastatic lymph nodes (N1 tumors) the serum levels of MMP-2 and TIMP-2 were lower than in N0 subgroup, but the differences did not reach statistical significance. The concentrations of tumor markers were higher in patients with nodal metastases, but the differences were significant only for CEA ( $p=0.017)$. In M1 subgroup (patients with distant metastases) the concentrations of TIMP-2, CEA and SCC increased, but MMP-2 decreased in comparison with M0 subgroup. These differences were also not significant in Mann-Whitney test. The concentrations of all proteins tested were the highest in patients with moderately differentiated tumors (G2) but the differences between subgroups analyzed were not significant. Moreover, the results of comparison with control group were similar to cancer stages - the concentrations of MMP-2 and TIMP-2 in all analyzed subgroups (nodal involvement, presence of distant metastases and differentiation of tumor) were significantly lower, whereas CEA significantly higher than in healthy subjects. These findings were confirmed in Spearman rank correlation test, where concentrations of CEA significantly correlated with nodal involvement $(\mathrm{p}=0.016)$ and tumor size $(\mathrm{p}=0.016)$ but MMP-2 with serum levels of TIMP-2 ( $<<0.001)$.

\section{Correlations between MMP-2, TIMP-2, CEA and SCC serum levels and prognosis of patients' survival}

Univariate analysis (Table 4) showed that tumor stage $(\mathrm{p}<0.001)$, depth of tumor invasion $(\mathrm{p}<0.001)$, presence of distant metastases $(\mathrm{p}<0.001)$, tumor size $(\mathrm{p}=0.016)$, resection of tumor $(\mathrm{p}=0.005)$ and serum levels of SCC ( $\mathrm{p}=0.003)$ were significant factors affecting patients' survival. Type of cancer, 


\begin{tabular}{|c|c|c|c|c|c|}
\hline \multirow{3}{*}{ 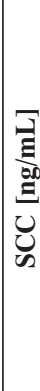 } & $=$ & $\stackrel{n}{0}$ & $\begin{array}{l}\bar{\Xi} \\
\dot{0} \\
\mathrm{v}\end{array}$ & 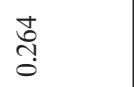 & 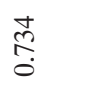 \\
\hline & 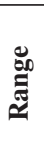 & 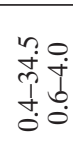 & 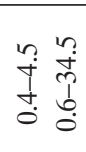 & 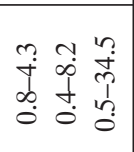 & 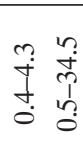 \\
\hline & 宽 & 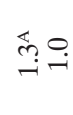 & g. & $\stackrel{\leftrightarrow}{\rightarrow} \underset{i}{\stackrel{c}{n}}$ & $\stackrel{\leftrightarrow}{\rightarrow} \stackrel{m}{-}$ \\
\hline \multirow{3}{*}{ 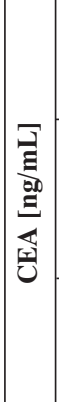 } & $=$ & $\begin{array}{l}\vec{\Xi} \\
\dot{0} \\
v\end{array}$ & $\begin{array}{l}n \\
0 \\
\infty \\
0\end{array}$ & 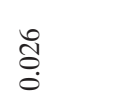 & $\begin{array}{l}\infty \\
\stackrel{0}{0} \\
\stackrel{0}{0}\end{array}$ \\
\hline & 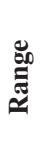 & 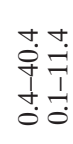 & 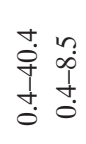 & 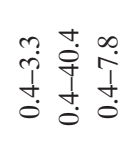 & 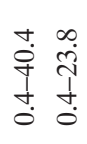 \\
\hline & 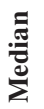 & 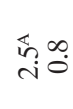 & in & 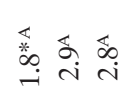 & 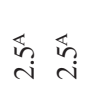 \\
\hline
\end{tabular}

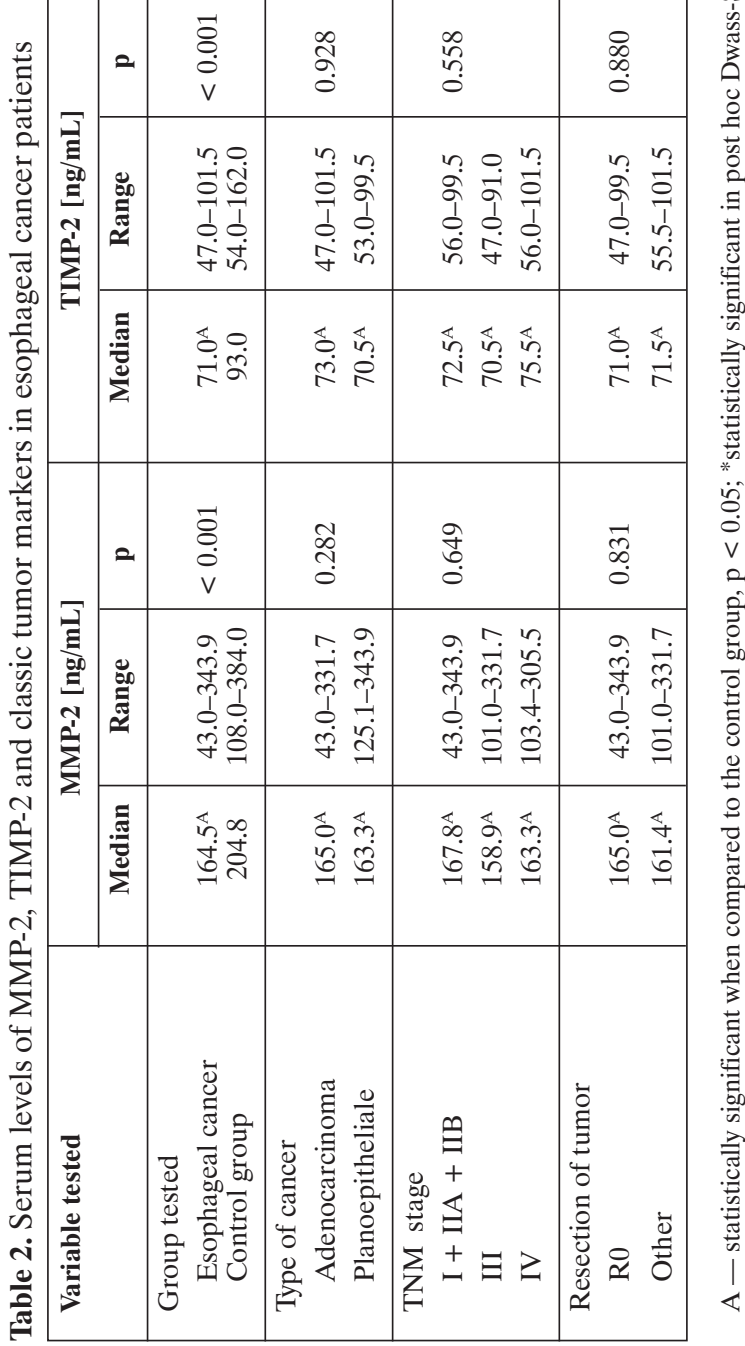

\begin{tabular}{|c|c|c|c|c|c|c|}
\hline \multirow{3}{*}{ 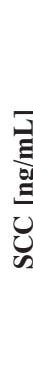 } & $=$ & $\stackrel{ }{\stackrel{1}{0}}$ & $\stackrel{\infty}{\circ}$ & $\begin{array}{l}\text { ̊̊ } \\
\text { อ̊ }\end{array}$ & $\underset{\exists}{\exists}$ & $\begin{array}{l}n \\
0 \\
0\end{array}$ \\
\hline & 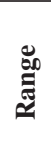 & $\begin{array}{ll}n & n \\
\dot{n} & + \\
0 & 0 \\
0 & + \\
0 & + \\
0\end{array}$ & 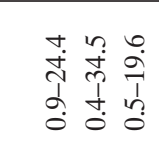 & 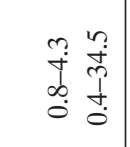 & $\begin{array}{ll}0 & n \\
0 & 0 \\
0 & 0 \\
0 & 1 \\
0 & n \\
0 & 1\end{array}$ & 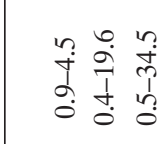 \\
\hline & 离 & $\stackrel{\leftrightarrow}{\rightarrow} \stackrel{?}{-}$ & 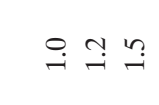 & $\stackrel{\circ}{\rightarrow} \stackrel{\leftarrow}{\rightarrow}$ & $\stackrel{\sim}{\rightarrow} \underset{\sim}{\sim}$ & 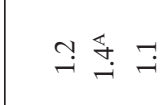 \\
\hline \multirow{3}{*}{ 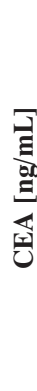 } & $=$ & 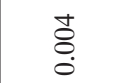 & 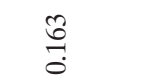 & 章 & $\stackrel{\infty}{\sigma}$ & $\begin{array}{c}\tilde{n} \\
\tilde{\sigma}\end{array}$ \\
\hline & 总 & 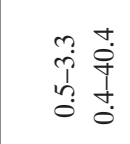 & 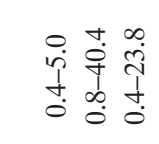 & 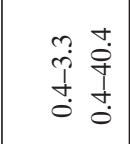 & $\begin{array}{l}\stackrel{\infty}{+} \\
\stackrel{\infty}{+} \\
\dot{j} \\
\dot{j} \\
\dot{0}\end{array}$ & 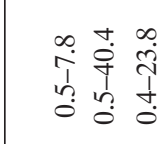 \\
\hline & 宽 & 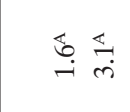 & $\stackrel{\infty}{\rightarrow} \stackrel{\substack{n \\
i}}{m}$ & 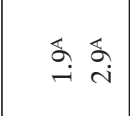 & 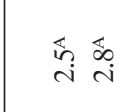 & 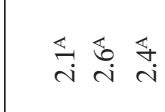 \\
\hline \multirow{3}{*}{ 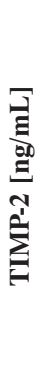 } & $=$ & 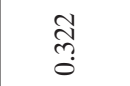 & 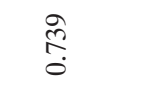 & $\begin{array}{c}\text { Î. } \\
\infty \\
0\end{array}$ & $\vec{m}$ & $\stackrel{0}{7}$ \\
\hline & 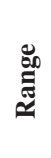 & 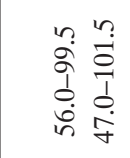 & 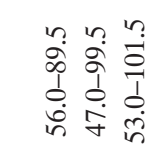 & 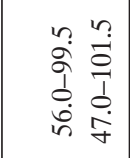 & 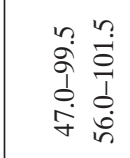 & 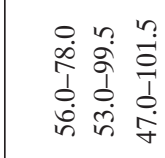 \\
\hline & & ind & 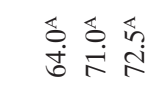 & 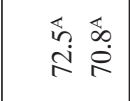 & 常点 & 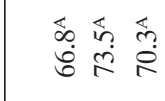 \\
\hline \multirow{3}{*}{ 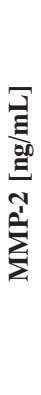 } & $=$ & 芯 & $\begin{array}{l}\infty \\
\stackrel{\infty}{0} \\
0\end{array}$ & 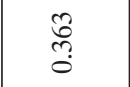 & $\begin{array}{l}\infty \\
\infty \\
0 \\
0\end{array}$ & है \\
\hline & 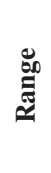 & 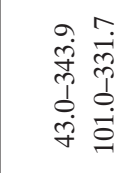 & 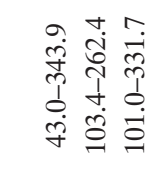 & 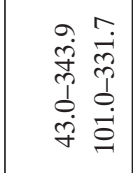 & 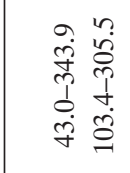 & 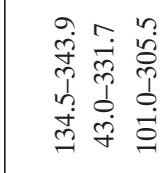 \\
\hline & 宽 & 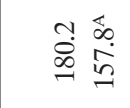 & 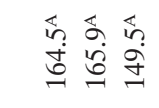 & 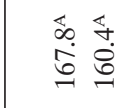 & 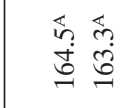 & 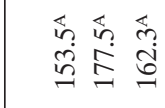 \\
\hline 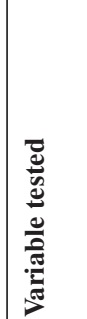 & & 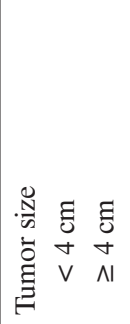 & 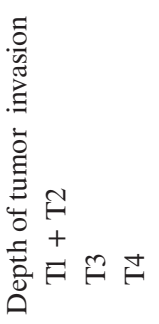 & 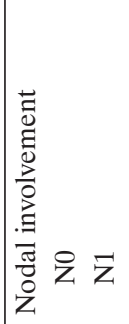 & 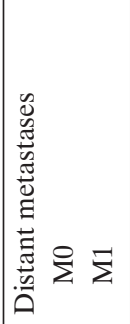 & 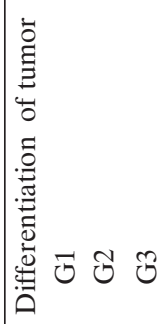 \\
\hline
\end{tabular}


Table 4. Results of Cox's univariate analysis in esophageal cancer patients

\begin{tabular}{|l|c|c|}
\hline Variable tested & OR & p \\
\hline Type of cancer & 2.143 & 0.073 \\
\hline Age & 0.997 & 0.899 \\
\hline Gender & 0.930 & 0.885 \\
\hline Tumor stage & & $<0.001^{*}$ \\
\hline TNM III $v$. TNM I+IIA+IIB & 0.910 & 0.854 \\
\hline TNM IV $v$ TNM I+IIA+IIB & 10.980 & $<0.001^{*}$ \\
\hline Depth of tumor invasion (T factor) & & $<0.001^{*}$ \\
\hline T3 $v$ T1+T2 & 0.680 & 0.490 \\
\hline T4 $v \cdot$ T1+T2 & 4.779 & $0.006^{*}$ \\
\hline Nodal involvement (N factor) & 1.443 & 0.415 \\
\hline Distant metastases (M factor) & 11.656 & $<0.001^{*}$ \\
\hline Differentiation of tumor & & 0.093 \\
\hline G2 $v$. G1 & 1.248 & 0.708 \\
\hline G3 v. G1 & 2.812 & 0.079 \\
\hline Tumor size & 1.224 & $0.016^{*}$ \\
\hline Resection of tumor & 215.956 & $0.005^{*}$ \\
\hline MMP-2 & 1.003 & 0.392 \\
\hline TIMP-2 & 1.031 & 0.079 \\
\hline CEA & 0.974 & 0.319 \\
\hline SCC & 1.072 & $0.003^{*}$ \\
\hline
\end{tabular}

*statistically significant when $\mathrm{p}<0.05$

patients age or gender, as well as nodal status, differentiation of tumor and concentrations of MMP-2, TIMP-2 and CEA were not significant prognostic factors. Multivariate regression analysis with Cox's pro- portional hazard model revealed that only tumor size was an independent prognostic factor for the survival of EC patients $(\mathrm{p}=0.008)$.

\section{The diagnostic usefulness of MMP-2, TIMP-2, CEA and SCC levels in EC patients' sera}

The percentage of true positive results of proteins tested in EC patients (diagnostic sensitivity) is presented on Figure 1. The diagnostic sensitivity of serum TIMP-2 levels (57\%; 95\% C.I.: 0,4327-0,6905) was higher than those of MMP-2 (40\%; 95\% C.I.: 0.2759-0,5306), CEA (30\%; 95\% C.I.: 0.1952-0.4354) and SCC (25\%; 95\% C.I.: 0.1493-0.3757). The frequency of true positive results was the highest for the combination of TIMP-2 with SCC $(70 \%$; $95 \%$ C.I.: $0.5646-0.8048)$ and with CEA $(66 \%$; $95 \%$ C.I.: $0.5259-0.7731)$.

Figure 2 presents ROC curves for all biomarkers analyzed. The TIMP-2 area under ROC curve (AUC = $=0.8698, \mathrm{p}<0.001$ when compared with $\mathrm{AUC}=0.5$ ) was higher than for CEA (AUC $=0.7958, \mathrm{p}<0.001$ ); MMP-2 (AUC $=0.7405, \mathrm{p}<0.001$ ) and for SCC $(\mathrm{AUC}=0.5695, \mathrm{p}=0.3520)$. Moreover, we compared AUC for subsequent proteins tested. The differences between AUC for TIMP-2 and for MMP-2 as well as between AUC for TIMP-2 and for SCC were significant $(\mathrm{p}=0.004$ and $\mathrm{p}<0.001$, respectively).

\section{Discussion}

Esophageal cancer still has a poor prognosis and is very difficult to cure. One of the reasons is an invasive character of tumor and its rapid growth. Although some of tumor markers have been tested for their usefulness in diagnosis of EC patients, estimating of

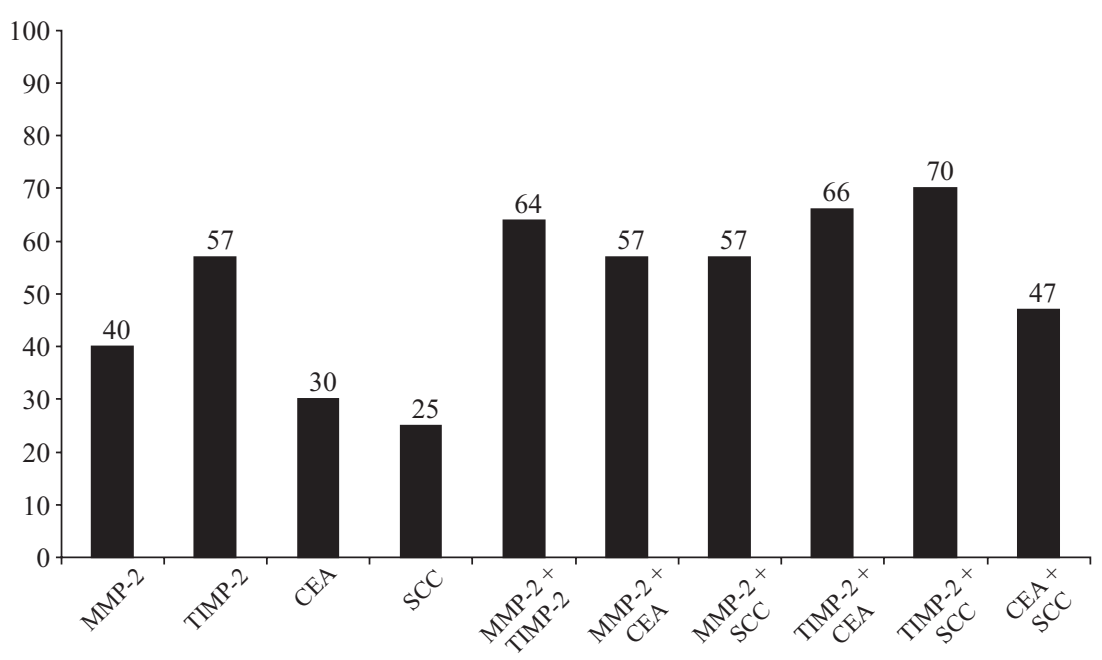

Figure 1. Diagnostic sensitivity (\%) of MMP-2, TIMP-2, CEA and SCC in esophageal cancer patients 


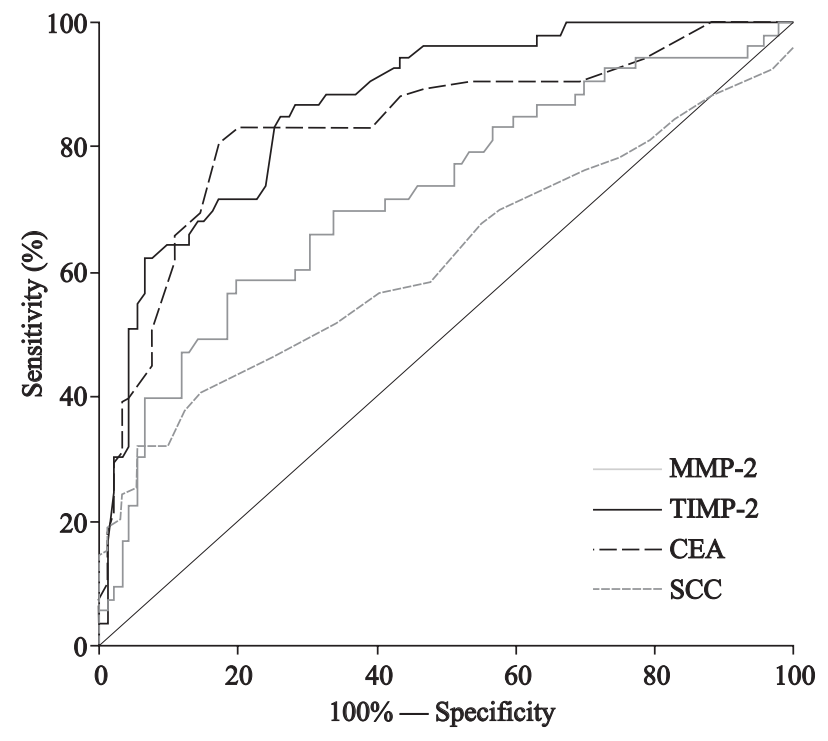

Figure 2. Areas under ROC curves (AUC) for TIMP-2 (0.8698), CEA (0.7958), MMP-2 (0.7405) and SCC (0.5695)

prognosis, monitoring of therapy and early detection of tumor recurrence, there are no suitable tumor markers of this malignancy. SCC and CEA are the tumor markers commonly used in the diagnostics of esophageal cancer, but their diagnostic sensitivity and specificity are still unsatisfactory [23, 24].

The most common technique of investigation the MMPs and TIMPs protein expression is evaluation of immunohistochemical staining, a semiquantitive and subjective method. This method of investigation employs tissue samples preparation and may additionally be limited by sensitivity of monoclonal antibodies. The direct measurement of MMP-2 and TIMP-2 levels in cancer tissues, using real-time PCR, would probably better reflect the production of these proteins in cancer cells, but requires more sophisticated techniques. On contrary, immunoenzymatic determination of MMPs and TIMPs levels in serum of esophageal cancer patients may be performed before treatment and is more simple method of detection. So far, in contrast to tissue expression, little is known about concentrations of MMP-2 and TIMP-2 in the blood of EC patients. Therefore, this report aims to examine the diagnostic significance of the measurement of pretreatment serum levels of MMP- 2 and TIMP- 2 in patients with esophageal cancer, especially in the diagnosis and prognosis of their survival.

The classic tumor markers for EC - CEA and SCC, which are currently used as biomarkers of tumor burden in clinical practice, were used as reference markers. The concentrations of MMP-2 and TIMP-2 and classic tumor markers in the sera of fif- ty-three EC patients were assessed in relation to clinico-pathological features of tumor, such as cancer stage, histological type of cancer, tumor size, depth of tumor invasion ( $\mathrm{T}$ factor), involvement of regional lymph nodes ( $\mathrm{N}$ factor), presence of distant metastases ( $\mathrm{M}$ factor), differentiation of tumor and resection of tumor. Additionally, we compared serum levels of proteins tested in ninety-two healthy controls.

In the current study the pretreatment serum levels of CEA and SCC were significantly higher in EC patients than in healthy subjects, what is in line with our previous studies on esophageal cancer [21]. Serum concentrations of MMP-2 and TIMP- 2 in cancer group were significantly lower than in healthy controls. The obtained results are in accordance with our previous studies on colorectal [25] and gastric cancer [26] and with results of other authors who examined serum or plasma levels of those proteins in malignancies of alimentary tract, e.g. colorectal cancer [27]. Moreover, in the study of Oberg et al., the serum levels of the MMP-2/TIMP-2 complexes were significantly lower in CRC patients as compared to healthy blood donors, however, the serum concentrations of free MMP-2 and total amount of TIMP-2 were significantly higher in comparison with control group [28]. Similarly, Waas et al. in their study revealed that CRC patients exhibited significantly lower plasma levels of circulating pro-MMP-2 in comparison with healthy controls, independent on technique of determination (zymography versus ELISA method) [29]. Results obtained by Fujimoto and coworkers in gastric and pancreatic cancer patients are similar - they found free and complexed proMMP-2 serum levels to be lower than in healthy subjects [30]. On contrary, in the study of Endo et al. it was indicated, that serum and plasma levels of proMMP-2 in gastric cancer patients were significantly higher in comparison to healthy individuals [31]. It may suggest that in EC development an imbalance between MMP-2 and TIMP-2 occurs. Probably, the determination of the levels of the complexes of MMP-2/TIMP-2 in sera of EC patients in further study would help recognize this imbalance. Additionally, these results indicate that differences between cancer patients and healthy subjects could depend on the type of cancer.

The possible reason of decreased levels of MMP-2 and TIMP-2 in EC patients might be a formation of immunological complexes of the enzyme and its inhibitor, what results in changes of their immunoreactivity in ELISA assays, although this hypothesis requires further studies. The exact biochemical and physiological relation between MMPs and TIMPs is still not completely elucidated as well as the interactions with other biologically active factors in the ECM. 
One of the explanations might be that reduced MMP-9 plasma levels lead to decrease of the synthesis of angiostatin, with a consequent increase in tumor growth and vascularization, which was found by Pozzi et al. [32]. It is possible, that such mechanism might also apply to MMP-2, although this issue requires further investigations.

In our study the concentrations of MMP-2 and TIMP-2 in the sera of EC patients did not correlate significantly with tumor stage, resectability of tumor, tumor size, depth of tumor invasion, nodal involvement, presence of distant metastases or differentiation of tumor. However, serum levels of both proteins tended to be lower in more advanced tumors. The decrease of serum MMP-2 and TIMP-2 in patients with nodal involvement and with tumors greater than $4 \mathrm{~cm}$ might reflect formation of MMP-TIMP complexes in esophageal tumor progression. It suggests that use of MMP-2 and TIMP-2 in combination with different imaging techniques could be a predicting tool giving important preoperative information in staging of EC patients. The serum levels of CEA increased significantly with tumor stage, tumor size and presence of nodal metastases, what is in line with our previous study [33].

We also investigated whether the decreased serum concentrations of MMP-2 and TIMP-2 might be useful prognostic factors for survival of patients with esophageal cancer. The univariate analysis showed that only serum level of SCC as well as cancer stage, $\mathrm{T}$ and $\mathrm{M}$ factors, tumor size and tumor resectability were significant prognostic factors in EC patients. Consequently, all these variables included in the multivariate regression analysis, revealed that only tumor size may be an independent prognostic factor predicting EC patients' survival. Obtained results are in line with those of Murray et al., who showed that the expression of MMP-2 in esophageal cancer tissue have no potential value as prognostic markers in EC, although, they did not examine the prognostic significance of TIMP-2 [34]. However, prognostic significance of TIMP-2 expression in esophageal cancer tissue was demonstrated by Sharma et al. [17].

In the present paper, we defined the diagnostic sensitivity as frequency of true positive results and AUC for all proteins tested to assess a potential diagnostic significance of MMP-2 and TIMP-2 as tumor markers in EC. According to our knowledge, this is the first study comparing diagnostic usefulness of these biomarkers in patients with esophageal cancer. We revealed that the diagnostic sensitivity of TIMP-2 $(57 \%)$ and MMP-2 (40\%) were higher than frequency of elevated levels of both classic tumor markers $(\mathrm{CEA}-30 \%$, SCC $-25 \%)$. The diagnostic sensi- tivity of proteins tested increased with their combined use and was the highest for TIMP-2 with SCC (70\%) and much higher than for combined use of classical tumor markers for EC - CEA with SCC (47\%). Moreover, we demonstrated, that AUC for TIMP-2 measurement (0.8698) was higher than for other proteins tested, e.g CEA (0.7958), MMP-2 (0.7405) and SCC (0.5695). Obtained results indicate the diagnostic significance of TIMP-2 in esophageal cancer but we are going to include benign and precancerous esophageal diseases to clarify the possible usefulness of biomarkers evaluated.

In conclusion, our findings suggest the usefulness of TIMP-2 in the diagnosis of esophageal cancer, especially in combined use with classic tumor markers of EC, e.g. CEA or SCC. However, the further investigations are necessary.

\section{References}

1. Crew KD, Neugut A. Epidemiology of upper gastrointestinal malignancies. Semin Oncol. 2004;31:450-464.

2. Pohn H, Welch HG. The role of overdiagnosis and reclassification in the marked increase of esophageal adenocarcinoma incidence. J Natl Cancer Inst. 2005;97:142-146.

3. Parkin MD, Bray F, Ferlay J, Pisani P. Global cancer statistics, 2002. CA Cancer J Clin. 2005;55:74-108.

4. Blot WJ, McLaughlin JK, Fraumeni JF Jr. Esophageal cancer. In: Schottenfeld D, Fraumeni JF Jr., ed. Cancer Epidemiology and Prevention. New York: Oxford University Press; 2006:697-706.

5. El-Shahat M, Lotfy M, Fahmy L et al. Prognostic value of microvessel density, matrix metalloproteinase- 9 and $\mathrm{p} 53$ protein expression in esophageal cancer.J Egypt Natl Cancer Inst. 2004;16:224-230.

6. Vallbohmer D, Lenz HJ. Predictive and prognostic molecular markers in outcome of esophageal cancer. Dis Esophagus. 2006;19:425-432.

7. Samantaray S, Sharma R, Chattopadhyaya TK et al. Increased expression of MMP-2 and MMP-9 in esophageal squamous cell carcinoma. J Cancer Res Clin Oncol. 2004;130:37-44.

8. Gu ZD, Li JY, Li M et al. Matrix metalloproteinases expression correlates with survival in patients with esophageal squamous cell carcinoma. Am J Gastroenterol. 2005;100: $1835-1843$.

9. Sato H, Kida Y, Mai M et al. Expression of genes encoding type IV collagen-degrading metalloproteinases and tissue inhibitors of metalloproteinases in various human tumor cells. Oncogene. 1992;7:77-83.

10. Vihinen P, Kahari VM. Matrix metalloproteinases in cancer: prognostic markers and therapeutic targets. Int J Cancer. 2002;99:157-166.

11. Talvensaari-Mattila A, Paakko P, Turpeenniemi-Hujanen T. Matrix metalloproteinase-2 (MMP-2) is associated with survival in breast carcinoma. Br J Cancer. 2003;89:1270-1275.

12. Kubben FJ, Sier CF, Meijer MJ et al. Clinical impact of MMP and TIMP gene polymorphisms in gastric cancer. Br J Cancer. 2006;95:744-751.

13. Giannopoulos G, Pavlakis K, Parasi A et al. The expression of matrix metalloproteinases- 2 and -9 and their tissue inhibitor 2 in pancreatic ductal and ampullary carcinoma and their 
relation to angiogenesis and clinicopathological parameters. Anticancer Res. 2008;28:1875-1881.

14. Murnane MJ, Cai J, Shuja S, McAneny D, Klepeis V, Willett JB. Active MMP-2 effectively identifies the presence of colorectal cancer. Int J Cancer. 2009;125:2893-2902.

15. Li Y, Ma J, Guo Q et al. Overexpression of MMP-2 and MMP-9 in esophageal squamous cell carcinoma. Dis Esophagus. 2009;22:664-667.

16. Yu C, Zhou Y, Miao X, Xiong P, Tan W, Lin D. Functional haplotypes in the promoter of matrix metalloproteinase-2 predict risk of the occurrence and metastasis of esophageal cancer. Cancer Res. 2004;64:7622-7628.

17. Sharma R, Chattopadhyay TK, Mathur M, Ralhan R. Prognostic significance of stromelysin-3 and tissue inhibitor of matrix metalloproteinase-2 in esophageal cancer. Oncology. 2004;3-4:300-309.

18. Chen YK, Chang WS, Wu IC et al. Molecular characterization of invasive subpopulations from an esophageal squamous cell carcinoma cell line. Anticancer Res. 2010;3:727-736.

19. Chen W, Abnet CC, Wei WQ et al. Serum markers as predictors of esophageal squamous dysplasia and early cancer. $A n-$ ticancer Res. 2004;24:3245-3249.

20. Sobin LH, Wittenkind C. International Union Against Cancer (UICC) TNM classification of malignant tumours, $5^{\text {th }}$ edition. New York: Willey-Liss;1997.

21. Mroczko B, Kozłowski M, Groblewska M et al. The diagnostic value of the measurement of matrix metalloproteinase 9 (MMP-9), squamous cell cancer antigen (SCC) and carcinoembryonic antigen (CEA) in the sera of esophageal cancer patients. Clin Chim Acta. 2008;389:61-66.

22. Newcombe RG. Two-sided confidence intervals for the single proportion: Comparison of seven methods. Stat Med. 1998:17:857-872.

23. Brockmann JG, St Nottberg H, Glodny B, Heinecke A, Senninger NJ. CYFRA 21-1 serum analysis in patients with esophageal cancer. Clin Cancer Res. 2000;6:4249-4252.

24. Shimada H, Nabeya Y, Tagawa $M$ et al. Preoperative serum midkine concentration is a prognostic marker for esophageal squamous cell carcinoma. Cancer Sci. 2003;94:628-632.

25. Groblewska M, Mroczko B, Gryko M, Kędra B, Szmitkowski M. Matrix metalloproteinase 2 and tissue inhibitor of matrix metal- loproteinases 2 in the diagnosis of colorectal adenoma and cancer patients. Folia Histochem Cytobiol. 2010;48:564-571.

26. Mroczko B, Lukaszewicz-Zając M, Gryko M, Kędra B, Szmitkowski M. Clinical significance of serum levels of matrix metalloproteinase 2 (MMP-2) and its tissue inhibitor (TIMP-2) in gastric cancer. Folia Histochem Cytobiol. 2011; 49:125-131.

27. Waas E, Wobbes T, Ruers T, Lomme R, Hendriks T. Circulating gelatinases and tissue inhibitor of metalloproteinase-1 in colorectal cancer metastatic liver disease. Eur J Surg Oncol. 2006;32:756-763

28. Oberg A, Höyhtyä M, Tavelin B, Stenling R, Lindmark G. Limited value of preoperative serum analyses of matrix metalloproteinases (MMP-2, MMP-9) and tissue inhibitors of matrix metalloproteinases (TIMP-1, TIMP-2) in colorectal cancer. Anticancer Res. 2000;20:1085-1091.

29. Waas E, Hendriks T, Lomme R, Wobbes T. Plasma levels of matrix metalloproteinase-2 and tissue inhibitor of metalloproteinase-1 correlate with disease stage and survival in colorectal cancer patients. Dis Colon Rectum. 2005;48: 700-710.

30. Fujimoto N, Mouri N, Iwata K, Ohuchi E, Okada Y, Hayakawa T. A one-step sandwich enzyme immunoassay for human matrix metalloproteinase 2 (72-kDa gelatinase/type IV collagenase) using monoclonal antibodies. Clin Chim Acta 1993;221:91-103.

31. Endo K, Maehara Y, Baba $\mathrm{H}$ et al. Elevated levels of serum and plasma metalloproteinases in patients with gastric cancer. Anticancer Res. 1997;17:2253-2258.

32. Pozzi A, LeVine WF, Gardner HA. Low plasma levels of matrix metalloproteinase 9 permit increased tumor angiogenesis. Oncogene 2002;21:272-81.

33. Łukaszewicz-Zając M, Mroczko B, Kozłowski M, Nikliński J, Laudański J, Szmitkowski M. Clinical significance of serum macrophage-colony stimulating factor (M-CSF) in esophageal cancer patients and its comparison with classical tumor markers. Clin. Chem. Lab. Med. 2010;48:1467-1473.

34. Murray GI, Duncan ME, O’Neil P, McKay JA, Melvin WT, Fothergill JE. Matrix metalloproteinase-1 is associated with poor prognosis in oesophageal cancer. J. Pathol. 1998;185: 256-261. 